\title{
Student Stress and Academic Satisfaction: A Mixed Methods Exploratory Study
}

\author{
Iffat Naeem, Fabiola E. Aparicio-Ting, Patti Dyjur \\ University of Calgary, Canada
}

\begin{abstract}
Student satisfaction has implications for student academic success, engagement, and retention within their programs. The aim of this study is to explore the relationship between three levels of student stress and satisfaction in an undergraduate program. To explore: 1) the distribution of stress and program satisfaction within the program; 2) associations between measures of student stress and program level satisfaction; and 3) student perceptions about stress and program satisfaction using qualitative data. Online questionnaires were administered to 24 students in a small, undergraduate health sciences honours program. Correlational analysis was used to fulfill the objectives, which were triangulated with qualitative data. Levels of stress were low and academic satisfaction high within this program. Qualitative results suggest a small program size and social support as explanatory factors. A negative correlation was found between burnout and overall program satisfaction. Qualitative findings indicate that program context and individual characteristics may describe this association. This study has implication in promoting adaptive personality traits within students and facilitating supportive and engaging program environments to ensure student success.
\end{abstract}

\section{Introduction}

Stress can be defined as an imbalance between the demands of life and the resources required to meet those demands, resulting in a feeling of being overwhelmed [1]. Stress can have both psychological and physical components, all of which can be detrimental to wellbeing. Students in higher education tend to feel the acute and sustained effects of stress at a higher proportion than other populations [1,2]. Indeed, students in higher education undergo a unique transitional experience of losing the support and structure of family and high school, and must learn to handle demanding curricula and personal, financial, and familial obligations [1].

Student satisfaction can be defined as the perception of contentment with university experiences, and the extent to which students feel their expectations for their learning are met while at an academic institution [3]. Satisfaction at the program level is influenced by multiple contextual factors, including the learning environment, courses, and administration [4]. Conant, Brown, and Mokwa [5] believed higher education to be a complex 'service' product, pushing researchers to explore the dynamics and multifactorial nature of student satisfaction. Postsecondary institutions recognize student satisfaction to be an important measure of not only student success and outcomes, but also measures of program quality [6]. Specifically, student retention at the postsecondary level is associated with student satisfaction, and indirectly measures the quality of educational programs [7].

The relationship between stress and programlevel satisfaction remains underexplored. Studies have shown student satisfaction to be linked to psychological wellbeing, where a lack of social support, unhealthy work life balance, and stress are associated with lower satisfaction and subsequent retention within a program $[3,6,8]$. High levels of stress are associated with poor academic performance resulting from an inability to manage workloads, testing conditions, and deadlines, which may explain lower satisfaction levels [9]. Other studies have found higher levels of stress to be related to higher satisfaction, where some rigorous programs have focused on positive stress appraisal to produce higher satisfaction rates for students $[10,11]$. Grayson [4] has shown that the strongest predictor of program-level satisfaction is satisfaction within the previous year, interpreted by the authors to mean that underlying personality characteristics are partly responsible for program satisfaction in higher education. This is corroborated by Carton and Goodboy [2], who discuss that student levels of engagement, self-esteem, and social competencies are predictors of satisfaction within a program.

To ensure academic success and retention in higher education, it is important to understand the complex nature of satisfaction within this context. Therefore, the exploration between stress and program satisfaction is an important endeavor [3]. We aim to further explore the association between measures of student stress and program-level 
satisfaction in a small honours Health Science undergraduate program. Our study employs three measures of student stress: a global measure, burnout, and spillover; and three measures associated with program satisfaction: overall program satisfaction, a sense of belonging to a learning community, and academic satisfaction. This study takes a mixed methods exploratory approach to fulfill the following objectives: 1) explain the distribution of stress and program satisfaction within the program; 2) find associations between measures of student stress and program level satisfaction; and 3) to explore student perceptions about stress and program satisfaction using qualitative data.

\section{Methods}

\subsection{Context}

The study is part of a larger project assessing the impacts of curriculum review processes on an honours undergraduate Health Science program (Health and Society; HSOC). This is a small program, with less than 20 students in each of the four years of study. Students are admitted into the program based on high academic achievement and a set of short response questions. To continue in the program, students are expected to achieve high academic performance and an honours GPA of 3.3 (out of 4) or higher. The present study analyzes data collected from an online student questionnaire about the program learning outcomes, courses experience, measures of student stress, and student demographics.

\subsection{Participants}

Ethics approval for the overall study was received from the University of Calgary Conjoint Faculties Research Ethics Board (REB17-1117). Students were recruited from core courses of the program at all levels of program progression. The purpose of the study was communicated to students orally, and they were given the opportunity to receive more information about the project. All students who expressed interest were contacted via email with additional information about the project and an invitation to participate in the online questionnaire, which included an online consent form. The first round of questionnaires was administered via Qualtrics ${ }^{\mathrm{TM}}$ software (Qualtrics, Provo, UT) to students in April of 2018, with a subsequent round in September and October of 2018.

\subsection{Measures}

2.3.1. Global Level of Stress. Three measures were used to encapsulate student stress within the study.
First, students were asked to rate their overall or global level of stress with the prompt "How would you describe your average level of stress over the past academic year?". Response choices ranged from $0=$ not at all stressed, $1=$ slightly stressed, $2=$ stressed, to $3=$ highly stressed.

2.3.2. Burnout. Burnout is a term used to explain complex psychological and emotional phenomenon related to emotional exhaustion, lack of individual perception of being unable to meet personal and professional goals [9]. Popularization of the concept led to development of the Maslach Burnout Inventory (MBI), which defines burnout as a syndrome composed of emotional exhaustion, depersonalization, and reduced personal accomplishment [12]. Burnout has been associated with personality characteristics, social support, and program contextual factors (e.g. workload): however, stress has been identified as an important component of burnout [13]. We used the MBI General Survey for Students (MBI-GSS), which consists of a 16-item scale made of 3 subscales measuring exhaustion; cynicism; and professional efficacy. The MBI-GSS measures the amount of times a student experiences each item on the scale (e.g. I feel emotionally drained by my studies) on a 7 point Likert scale $(0=$ never, $1=\mathrm{a}$ few times a year, $2=$ Once a month, $3=\mathrm{A}$ few times a month, 4=Once a week, 5=A few times a week, 6=Every day). Positive items on the scale (e.g. In my opinion I am a good student) were reverse coded. Means of all items in the inventory were obtained for each student. The Cronbach's alpha, a measure of internal reliability of the inventory, is 0.87 [14].

2.3.3. School Spillover. School spillover describes the spillover of stress from the academic context onto other contexts such as home life. This spillover can result in serious implications on student life, student success, and ultimately results in negative behavioral outcomes as a function of mental health problems [15]. This study utilizes a school spillover questionnaire employed by Pedersen and Jodin [1], which includes 11 items focusing on spillover faced by college students, including such items as "I've had to cancel plans with friends or family because of homework" and "sometimes I have to cut back on sleep to finish all my homework". The questionnaire items are rated on a 5-point Likert scale ( $1=$ strongly disagree, $2=$ disagree, $3=$ neither agree nor disagree, $4=$ agree, $5=$ strongly agree). Means of all items in the scale were obtained for each student. Cronbach alpha is 0.96 .

2.3.4. Course Experience Questionnaire. The short form of the Course Experience Questionnaire (CEQ) was used to evaluate the effectiveness of programs for student learning from the student perspective. 
The questionnaire measures aspects of good teaching practices, openness to students, freedom in learning, clear goals and standards, and appropriate workload. These aspects of the program have direct implications to student satisfaction and positive learning outcomes [16]. The CEQ was adapted to reflect the Health and Society program (e.g. "The Health and Society Program has helped me to develop my problem-solving skills"). The questionnaire contains 24 such items and is scaled in agreement using a 5-point Likert scale (1=strongly agree, $2=$ disagree, $3=$ neither agree nor disagree, 4=agree, 5=strongly agree). Negative items were reverse coded (e.g. "the workload is too heavy"). Means of all items in the questionnaire were obtained for each student. Cronbach's alpha for this questionnaire was 0.83 .

2.3.5. Learning Community Scale. The Learning Community Scale (LCS) contains 6 items focusing on student belonging, acceptance, and intellectual exploration [17]. The scale was adapted for the Health and Society Program (e.g. "I felt I belonged to a community of Health and Society students"). The 6 items were scaled on a 5-point Likert scale (1=strongly agree, $2=$ disagree, $3=$ neither agree nor disagree, $4=$ agree, $5=$ strongly agree). Means of all items in the questionnaire were obtained for each student. Cronbach's alpha for this scale was 0.53.

2.3.6. Qualitative Questions. The online questionnaire included three open-ended questions: 1) What are the best aspects of the Health \& Society program?; 2) What aspects of the Health \& Society program are in need of improvement?; and 3) In what ways do you think that the Bachelor of Health Sciences and Health \& Society program could better support student well-being and mental health?

\subsection{Data Analysis}

Quantitative data were analyzed using STATA 13. For the Likert Scale items (MBI, SSM, CEQ, LCS, and Academic Satisfaction Scale), descriptive statistics were provided in the form of means, standard deviations, minimum, and maximums. For global stress measure, the median, minimum, and maximum were provided. To explore the relationships between School Spillover Measures, Maslach Burnout Scale and all satisfaction measures, the Spearman's correlation co-efficient was calculated. Spearman's coefficients are a common mode of analysis for Likert scales, exploring the strength of the relationship between means of two scales [18]. For the global stress measure, a Likert type item and an ordinal variable, the Kendall tau correlational analysis was done [18]. The range of all co-efficient is between +1 to -1 , where the positive sign indicates that an increase in one variable results in an increase in the second, and vice versa for the negative. Correlation close to or beyond +0.70 or 0.70 indicate a strong relationship; correlations closer to +0.50 and -0.50 show a moderate relationship [18]. The level significance was set at $\alpha$ $=0.05$.

Qualitative data were analyzed using QSR International's NVivo $12^{\mathrm{TM}}$ software. The results for the qualitative open-ended questions were thematically analyzed for any discussion on stress and/or satisfaction at the program level. The themes were triangulated with the quantitative results to support our findings.

\section{Results}

\subsection{Descriptive Statistics}

Although 24 students consented to completing the online questionnaire, only 19 students provided enough information to be included in these analyses, of which 16 provided full demographic data. Four $(25 \%)$ of the students were male, while $12(75 \%)$ were female. The mean age of students within the program was 20 . Half of the students $(\mathrm{N}=8)$ were employed, and consistent with program requirements, almost all students reported a GPA of 3.3/4 or higher (see Table 1).

Table 1. Demographic Characteristics of Students

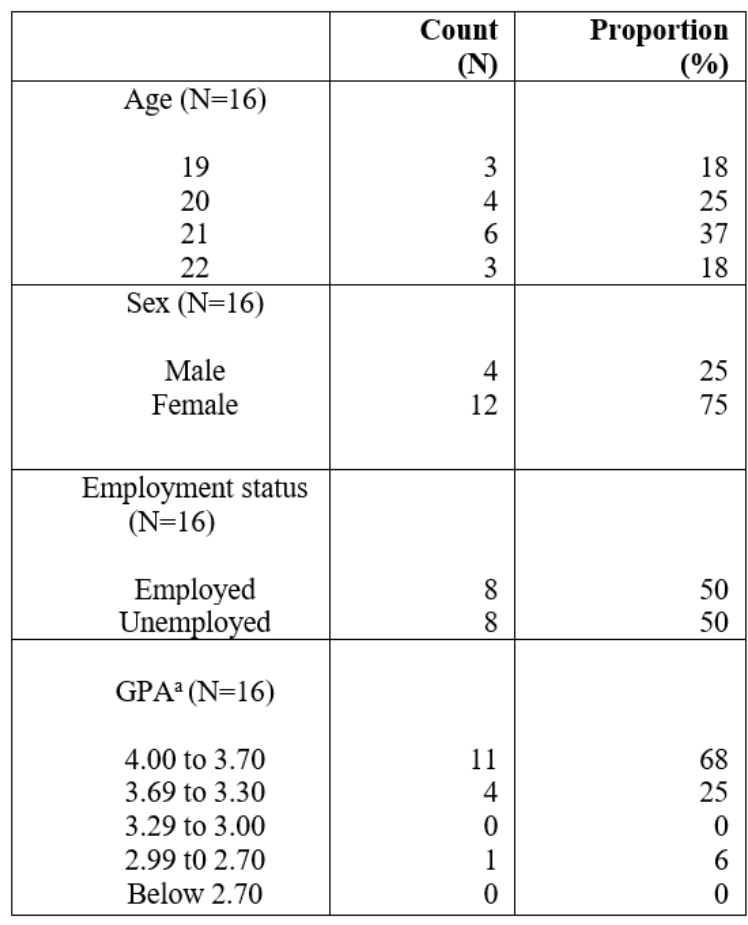

${ }^{\text {a }}$ GPA calculated on a four-point scale 
Most students $(\mathrm{n}=15)$ described some level of stress within the past academic year (see Figure 1). The mean MBI score was $2.2(\mathrm{SD}=0.71)$, where on average students experienced burnout 'once a month or less' within their program. The SSM had a mean of 3.3 ( $\mathrm{SD}=1.0)$, indicating that student on average 'neither agreed nor disagreed' with aspects of spillover within lives (neutral).

The Academic Satisfaction and fit scale had a mean of $4.3(\mathrm{SD}=0.42)$ and $4.1(\mathrm{SD}=0.46)$ respectively, indicating that on average students 'agreed' with positive aspects of program satisfaction, learning environment, goals setting, and employability within their program. The LCS had a mean of $4.0(\mathrm{SD}=0.47)$, indicating on average that students 'agreed' with positive aspects of the belonging and community within their program.

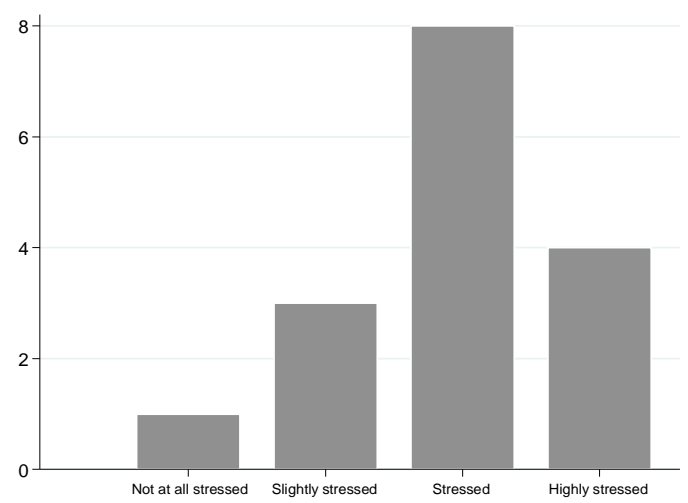

Figure 1. Global measure of stress of students in an honours undergraduate Health Science program over the past academic year

Finally, the CEQ had a mean of $3.74(\mathrm{SD}=0.44)$ meaning students on average ranged from 'neither agreed nor disagreed' and 'agreed' in positive aspects of teaching practices, learning environment, and workload (see Table 2).

Table 2. Descriptive statistics for measures used

\begin{tabular}{lcrcr}
\hline & Mean & $\begin{array}{r}\text { Stand } \\
\text { ard } \\
\text { Deviation }\end{array}$ & Min & Max \\
\hline $\begin{array}{l}\text { Course } \\
\begin{array}{l}\text { Experience } \\
\text { Questionnai }\end{array}\end{array}$ & 3.75 & 0.44 & 2.5 & 4.4 \\
$\begin{array}{l}\text { re (CEQ) } \\
\text { (N=19) }\end{array}$ & & & & \\
\hline $\begin{array}{l}\text { Learning } \\
\text { Community }\end{array}$ & 4.0 & 0.47 & 3.1 & 5 \\
$\begin{array}{l}\text { Scale (LCS) } \\
\text { (N=19) }\end{array}$ & & & & \\
\hline $\begin{array}{l}\text { Academic } \\
\text { Satisfaction }\end{array}$ & 4.3 & 0.42 & 3.6 & 5 \\
scale & & & & \\
(global & & & & \\
score) \\
(N=19)
\end{tabular}

\begin{tabular}{|c|c|c|c|c|}
\hline $\begin{array}{l}\text { Academic } \\
\text { Fit subscale } \\
(\mathrm{N}=19)\end{array}$ & 4.1 & 0.46 & 3.5 & 4.8 \\
\hline $\begin{array}{l}\text { Academic } \\
\text { Satisfaction } \\
\text { subscale } \\
(\mathrm{N}=19)\end{array}$ & 4.2 & 0.41 & 3.7 & 4.8 \\
\hline $\begin{array}{l}\text { School } \\
\text { Spillover } \\
\text { measures } \\
(\mathrm{SSM}) \\
(\mathrm{N}=16)\end{array}$ & 3.3 & 1.0 & 1.0 & 4.3 \\
\hline $\begin{array}{l}\text { Maslach } \\
\text { Burnout } \\
\text { Inventory } \\
(\mathrm{MBI}) \\
(\mathrm{N}=16)\end{array}$ & 2.2 & 0.71 & 1.1 & 3.3 \\
\hline
\end{tabular}

\subsection{Correlational Analysis}

Correlation analysis between student stress measures and program satisfaction measures are shown in Table 3. Amongst the stress variables, the MBI and SSM were moderately correlated $(r=0.56$, $\mathrm{p}=0.02$ ). Within the student satisfaction outcomes, the Academic Satisfaction Scale and CEQ were moderately correlated $(\mathrm{r}=0.64, \mathrm{p}=0.00)$. A significant negative correlation was found between the MBI and CEQ (r=-0.73, p=0.00).

\subsection{Qualitative Results}

When asked to comment on the best aspect of the Health and Society program, students reported on the supportive nature of the program, where the smaller class sizes and faculty involvement were highlighted as having positive impacts on student learning. Students commented:

The Health and Society student group is incredibly tight-knit and supportive. The smaller class sizes are perfect as they facilitate better discussion which I believe to be essential to the Health and Society field. This is the perfect program for me (student 4).

Although I am not directly privy to the interactions and involvement of the other streams, I believe that the HSOC students and staff are all on very good terms with one another and are invested in each other's success (student 4).

The Health and Society program has fantastic faculty and program directors. The professors are knowledgeable, enthusiastic, and care about each and every single student. The best thing about the program is that it is smaller. This allows me to get to know my profs and my peers on a personal level (student 8). 
Table 3. Correlations between measures of student stress and program level satisfaction within an honours undergraduate health science program

\begin{tabular}{|c|c|c|c|c|c|c|c|}
\hline & 1 & 2 & 3 & 4 & 5 & 6 & \\
\hline $\begin{array}{l}\text { 1. School Spill over } \\
\text { measure }\end{array}$ & - & & & & & & \\
\hline $\begin{array}{l}\text { 2. Average level of } \\
\text { stress }\end{array}$ & 0.38 & - & & & & & \\
\hline $\begin{array}{l}\text { 3. Maslach Burnout } \\
\text { Inventory }\end{array}$ & $0.56^{* *}$ & 0.25 & - & & & & \\
\hline $\begin{array}{l}\text { 4. Course experience } \\
\text { questionnaire }\end{array}$ & -0.33 & -0.09 & $0.73 * *$ & - & & & \\
\hline $\begin{array}{l}\text { 5. Learning } \\
\text { Community Survey }\end{array}$ & -0.32 & -0.18 & -0.36 & 0.18 & - & & \\
\hline $\begin{array}{l}\quad \text { 6. Academic } \\
\text { Satisfaction Scale (global } \\
\text { measure) }\end{array}$ & 0.19 & 0.18 & -0.44 & $0.64 * *$ & 0.25 & & - \\
\hline
\end{tabular}

Regarding aspects of the Health and Society program that needed improvement, student expressed a need for the program to better understand and to help alleviate the workload that students felt, which was a major stressor for students. As one student expressed,

I have seen all of my peers dangerously stressed out because of schoolwork at some point or another within the last couple of years, which may speak to workload.... (Student 19).

When asked how the Health and Society program could better support student wellbeing, students' responses indicated that they did not use mental health services but felt that the program could improve the availability of such services. Students also commented on the value of the one-on-one relationship between students and instructors as important in reducing stress. They stated:

There aren't really any resources for mental health on [our offsite] campus, and the wellness centre on main campus definitely needs work too. [Program] profs are generally really understanding and good at providing one on one support, but for more shy students or struggling students who have not developed that relationship, I can imagine it would be difficult (Student 8).

In my experience, there has been no outreach for providing students with mental health supports from the faculty. Professors are generally quite understanding and kind but I think particularly in a more intensive program ... the faculty should be proactive in supporting students' well-being and mental health.... (Student 6).

\section{Discussion}

This exploratory mixed methods study aimed to assess student stress and program level satisfaction in an honours undergraduate Health Science program. The results indicated that most students within the program experienced some level of stress, especially when assessed as a global measure of stress within the last year. The experience of stress within an undergraduate program was expected and is commonly reported within literature, where moderate levels of stress are viewed as beneficial to motivation and student performance $[1,19,20]$. Further, with the multifaceted etiology of stress, which may be from academic, personal, and financial pressures, the results are fitting within the context of students in higher education [19].

Students in our sample reported low levels of both school spillover and burnout. The qualitative results from the questionnaire indicated that the positive interactions between peers and faculty provided a supportive environment, which could have direct implications in student wellbeing. Research has reported on coping strategies as an important mediator between stress and outcomes such as academic satisfaction and learning [11]. Successful coping strategies by students are those that take on a problem-focused approach through effective use of resources, which can be in the form of support from peers, faculty, or administrators [9]. Social support has been found to act as a buffer against stressful circumstances [20]. The knowledgeable, enthusiastic, and understanding nature of faculty, as reported by students within this program, present a critical resource to elicit academic buoyancy: the ability for students be successful in navigating the demanding nature of their academic environments [21]. 
Overall, program satisfaction was high within the students of this program. Just as social support is related to positive stress appraisal and coping, the same can be said for program satisfaction [22]. Indeed, the students' qualitative data indicated the program's "tight knit" nature was a positive aspect which allowed closer interaction between peers and with faculty. Social support is critical to a student's adjustment, and research suggests that a high degree of continuity in an individual's quality of relationships is important in academic satisfaction [23]. Although perceived social support is well studied within the literature, the results of this study point towards program size as an important theme, a relatively less-researched concept within academic satisfaction literature. Studies have found that programs that are able to facilitate a feeling of being supported by faculty directly affects student effort (e.g. time spent studying), leading to improved satisfaction [22]. Smaller programs may be able to do this better, as faculty can dedicate more time to their students and understand their individualized needs. This type of personalized guidance and instruction is known to predict both psychosocial adjustment and academic satisfaction [24]. Further, the same sense of belonging and acceptance facilitated by a small program can improve student motivation and engagement within a program, both strong predictors of satisfaction [17].

Although students within this study reported low levels of burnout, a strong negative correlation between student-reported burnout and program satisfaction, as measured by the CEQ, was observed. Workload is an important aspect of the CEQ and has been found to be positively correlated with burnout, where overlap of assignments with other academic obligations (e.g. tests) can cause students to become overwhelmed and unprepared to take on the challenges of academic programs [25]. Qualitative results also highlight workload as a prominent stressor within the program and may be a contributing factor to those students reporting higher levels of burnout. Research suggests collaborative learning environments and innovative teaching initiatives aimed at increasing student self-efficacy and control are effective against student burnout [26].

Interestingly, although qualitative data suggested a strong supportive instructional environment within the program, the negative correlation between burnout and CEQ suggested that some students have reported high levels of burnout with low levels of satisfaction with instructional and faculty support (another aspect of the CEQ). This may be attributable to individual cognitive perspectives, personality, and motivational traits within students. For example, some personality traits such as neuroticism are known to predict lower program satisfaction [27]. Problem solving coping strategies have been associated not only with reduced stress, but also cognitive changes that promote support seeking [28]. Further, intrinsic motivations for starting a program and cognitive processes, such as self-regulated learning, both predict program satisfaction [27]. The effects of program context cannot be ignored when understanding the cost and benefit of certain traits within students as they enter a program [29]. This is especially the case for academically-intense programs that attract students with certain dispositions, such as those who are conscientious, confident, ambitious, and perfectionists [30].

\subsection{Study Strength and Limitations}

This study finds its strengths in the multifaceted measures employed to explore student stress and academic satisfaction. The study provides an indepth investigation in such measures within a small undergraduate program. Further, with the mixed methods design, the results are triangulated with qualitative data that adds depth to the results and discussion. The study's major limitation is its sample size, where correlational analysis may have been underpowered to find true association between the variables being studied. This also resulted in the lack of ability to carry out further analyses (e.g. regression analysis) to understand the direction and magnitude of association between predictor and explanatory variables. For example, understanding the effects of demographic variables on associations (e.g. age and gender) was not possible without a multivariate analysis, which this study was underpowered to do.

\subsection{Conclusions}

Student satisfaction is an important measure of institutional effectiveness for faculties, departments, and governing boards. At the student level, satisfaction affects success, learning outcomes, and retention rates within a program. We have shown that within a small undergraduate Health Sciences program, aspects of student stress are associated with program-level satisfaction. Small program size, which facilitated a supportive environment for students, is an important mechanism to cope with student stress. Further, both personality and contextual environment within a program influenced well-being and satisfaction. This has implications in promoting adaptive personality traits within students and facilitating supportive and engaging program environments to ensure student success. In order to be successful, academic programs should strive to take on a holistic approach to student stress by not only providing tailored support to students, but also improving their administrative and curricular structure to increase student satisfaction. 
Opportunities for further investigation lie in understanding the relationship between program size and student wellbeing and satisfaction. Further, the complex mediating role of coping strategies within individual students must be understood.

\section{References}

[1] Pedersen, D. E., \& Jodin, V. (2016) 'Stressors associated with the school spillover of college undergraduates', The Social Science Journal 53(1), pp. 4048.

[2] Carton, S. T., \& Goodboy, A. K. (2015) 'College students' psychological well-being and interaction involvement in class' Communication Research Reports 32(2), pp. 180-184.

[3] Hodge-Windover, S. T. (2017) 'The Relationship between Stress, Coping Style, and Academic Satisfaction: A Quantitative Study' (Unpublished doctoral dissertation), Northcentral University, California, USA.

[4] Grayson, J. P. (2004) 'The Relationship Between Grades and Academic Program Satisfaction Over Four Years of Study', Canadian Journal of Higher Education 34(2), pp. 1-34.

[5] Conant, J. S., Brown, J. J., \& Mokwa, M. P. (1985) 'Students are important consumers: Assessing satisfaction in a higher education context', Journal of Marketing Education 7(2), pp. 13-20.

[6] Butt, B. Z., \& Rehman, K. (2010) 'A study examining the student's satisfaction in higher education', ProcediaSocial and Behavioral Sciences 2(2), pp. 5446-5450.

[7] García-Aracil, A. (2009) 'European graduates' level of satisfaction with higher education', Higher Education 57(1), pp. 1-21.

[8] Eicher, V., Staerklé, C., \& Clémence, A. (2014) 'I want to quit education: A longitudinal study of stress and optimism as predictors of school dropout intention', Journal of Adolescence 37(7), pp. 1021-1030.

[9] Shelton Jr, I. G. (2017) 'A Generic Qualitative Investigation of Academic Stress in College Students in the 21 st Century' (Unpublished doctoral dissertation), Capella University, Florida, USA.

[10] Chraif, M. (2015) 'Correlative study between academic satisfaction, workload and level of academic stress at 3rd grade students at psychology', Procedia-Social and Behavioral Sciences, 203, pp. 419-424.

[11] Freire, C., Ferradás, M. D. M., Valle, A., Núñez, J. C., \& Vallejo, G. (2016) 'Profiles of psychological well-being and coping strategies among university students', Frontiers in psychology 7(1554), pp. 1-11.

[12] Maslach, C., Jackson, S. E., Leiter, M. P., Schaufeli, W. B., \& Schwab, R. L. (1986) Maslach burnout inventory, 21, 3463-3464. Palo Alto, CA: Consulting psychologists press.

[13] Jacobs, S. R., \& Dodd, D. (2003) 'Student burnout as a function of personality, social support, and workload', Journal of College Student Development 44(3), pp. 291303.

[14] Gliem, J. A., \& Gliem, R. R. (2003) 'Calculating, interpreting, and reporting Cronbach's alpha reliability coefficient for Likert-type scales', Proceedings of the Midwest Research-to-Practice Conference in Adult, Continuing, and Community Education, pp. 82-88.

[15] Pedersen, D. E., Swenberger, J., \& Moes, K. E. (2017) 'School spillover and college student health', Sociological Inquiry 87(3), pp. 524-546.

[16] Ramsden, P. (1991) 'A performance indicator of teaching quality in higher education: The Course Experience Questionnaire', Studies in Higher Education 16(2), pp. 129-150.

[17] Jansen, E. P. W. A., \& Suhre, C. J. M. (2015) 'Factors influencing students' perceptions of graduate attribute acquisition in a multidisciplinary honours track in a Dutch university', Higher Education Research \& Development 34(6), pp. 1138-1152.

[18] Murray, J. (2013) 'Likert data: what to use, parametric or non-parametric?', International Journal of Business and Social Science 4(11), pp. 259-264.

[19] Deasy, C., Coughlan, B., Pironom, J., Jourdan, D., \& Mannix-McNamara, P. (2014) 'Psychological distress and coping amongst higher education students: A mixed method enquiry', Plos One 9(12), pp. e115193.

[20] Julal, F. S. (2016) 'Predictors of undergraduate students' university support service use during the first year of university', British Journal of Guidance \& Counselling 44(4), pp. 371-381.

[21] Wibrowski, C. R., Matthews, W. K., \& Kitsantas, A. (2017) 'The role of a skills learning support program on first-generation college students' self-regulation, motivation, and academic achievement: A longitudinal study' Journal of College Student Retention: Research, Theory \& Practice 19(3), pp. 317-332.

[22] Fredrickson, J. E. (2012) 'Linking student effort to satisfaction: The importance of faculty support in creating a gain-loss frame', Academy of Educational Leadership Journal 16, pp. 111.

[23] Budescu, M., \& Silverman, L. R. (2016) 'Kinship support and academic efficacy among college students: A cross-sectional examination', Journal of Child and Family Studies 25(6), pp. 1789-1801.

[24] Friedlander, L. J., Reid, G. J., Shupak, N., \& Cribbie, R. (2007) 'Social support, self-esteem, and stress as predictors of adjustment to university among first-year 
undergraduates', Journal of college student development 48(3), pp. 259-274.

[25] Greenglass, E. R., Burke, R. J., \& Fiksenbaum, L. (2001) 'Workload and burnout in nurses', Journal of Community \& Applied Social Psychology 11(3), pp. 211215 .

[26] Koeske, G. F., \& Koeske, R. D. (1989) 'Work load and burnout: Can social support and perceived accomplishment help?', Social Work 34(3), pp. 243-248.

[27] Wach, F., Karbach, J., Ruffing, S., Brünken, R., \& Spinath, F. M. (2016) 'University students' satisfaction with their academic studies: Personality and motivation matter', Frontiers in Psychology 7(55), pp. 1-12.

[28] Neveu, D., Doron, J., Visier, L., Boiché, J., Trouillet, R., Dujols, P., \& Ninot, G. (2012) 'Students perceived stress in academic programs: Consequences for its management', Revue D'epidemiologie et de Sante Publique 60(4), pp. 255-264.

[29] Ferguson, E., Semper, H., Yates, J., Fitzgerald, J. E., Skatova, A., \& James, D. (2014) 'The 'dark side 'and 'bright side 'of personality: When too much conscientiousness and too little anxiety are detrimental with respect to the acquisition of medical knowledge and skill', PloS one 9(2), pp. e88606.

[30] Twenge, J. M. (2009) 'Generational changes and their impact in the classroom: teaching Generation Me', Medical education 43(5), pp. 398-405.

\section{Acknowledgments}

We would like to thank the students of the undergraduate Honours Health Science program for their willingness to share their views so freely. 